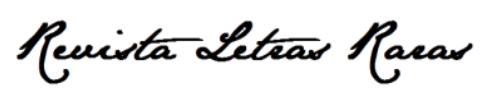

ISSN: 2317-2347 - v. 9, Dossier spécial (2020)

Todo o conteúdo da RLR está licenciado sob Creative Commons Atribuição 4.0 Internacional

\title{
O ensino de francês no Brasil oitocentista: uma história em
}

\section{quatro compêndios / L'enseignement du français au Brésil du}

\author{
XIXe siècle: une histoire en quatre manuels
}

\section{Kate Constantino Oliveira*}

Doctorante en éducation dans la ligne de recherche Education, Connaissances et Culture à de Universidade Federal de Sergipe (2018-2022). Master en éducation dans la ligne de recherche Education et formation des enseignants à l'Universidade Tiradentes (2016)..

(iD) https://orcid.org/0000-0003-4842-5959

Recebido : 22 set.. 2020. Aprovado: 24 out. 2020.

\section{Como citar este artigo:}

CONSTANTINO OLIVEIRA, Kate. O ensino de francês no Brasil oitocentista: uma história em quatro compêndios. Revista Letras Raras. Campina Grande, v. 9, p. 148-163, oct. 2020.

\section{RESUMO}

Este artigo investiga a história do ensino de francês no Brasil a partir de quatro compêndios disponíveis na América portuguesa na primeira década de 1800: Remarqves Svr La Langve Françoise, de Vaugelas; L'art De Bien Parler François, de Pierre De La Touche; Grammatica Franceza, Ou Arte Para Aprender O Francez Por Meio Do Portuguez, Regulada Pelas Notas E Refflexoens Da Academia De França, de Luís Caetano de Lima e Novo, E Facillimo Methodo De Grammatica Franceza, E Portugueza, Recopilado Dos Melhores Authores, publicado na oficina de António Ginião. Os livros compõem o acervo digital da Biblioteca Nacional do Rio de Janeiro, da Biblioteca Nacional de Portugal e da Bibliothèque Nationale de France. Foram analisados seus conteúdos de ensino que repercutem suas finalidades políticas e pedagógicas, justificada pelo uso nas cortes e depois como disciplina escolar (COMPĖRE; CHERVEL, 1999). Percebemos na análise descritiva um movimento na história do ensino de francês que vai da contemplação da língua e de seu ensino como arte ao entendimento lógico e racional de transmissão desse saber pela gramática. Observamos uma finalidade utilitarista no ensino de francês como código de acesso ao modelo de modernidade francês.

PALAVRAS-CHAVE: Ensino de língua francesa; História da educação; Compêndios de francês.

\section{RÉSUMÉ}

Cet article présente une histoire de l'enseignement du français au Brésil à partir de quatre manuels disponibles en Amérique portugaise au cours de la première décennie des années 1800: Remarqves Svr La Langve Françoise, de Vaugelas; L'art De Bien Parler François, de Pierre De La Touche; Grammatica Franceza, Ou Arte Para Aprender 0 Francez Por Meio Do Portuguez, Regulada Pelas Notas E Refflexoens Da Academia De França, de Luís Caetano de Lima et Novo, E Facillimo Methodo De Grammatica Franceza, E Portugueza, Recopilado Dos Melhores Authores, publié par António Ginião. Les livres constituent la collection numérique de la Bibliothèque Nationale de Rio de

\180liveira@gmail.com 


\section{Remita Lition Rear}

ISSN: 2317-2347 - v. 9, Dossier spécial (2020)

Todo o conteúdo da RLR está licenciado sob Creative Commons Atribuição 4.0 Internacional

Janeiro, de la Bibliothèque Nationale du Portugal et de la Bibliothèque Nationale de France. Les contenus pédagogiques de ces manuels, reflétant les finalités politiques et pédagogiques, ont été analysés, justifiés par l'usage à la cour et plus tard comme discipline scolaire (COMPĖRE; CHERVEL, 1999). On perçoit dans l'analyse descriptive un mouvement dans l'histoire de l'enseignement du français qui va de la contemplation de la langue et de son enseignement comme art à la compréhension logique et rationnelle de la transmission de ces connaissances par la grammaire. On observe une finalité utilitaire dans l'enseignement du français comme code d'accès au modèle de modernité française.

MOTS CLÉS: Enseignement du français; Histoire de l'éducation; Manuels de français.

\section{Introdução}

Para o desenvolvimento da instrução pública no Brasil oitocentista, que tinha por modelo de prosperidade a França, o ensino de francês se fazia necessário, funcionando esta língua como mediadora de acesso aos "códigos de civilização", segundo Lages (2013). Todavia, neste período, o trânsito das letras era lento e dispendioso, reflexo da censura de todo material impresso. Os livros, mediadores da "expressão dos valores culturais de um povo", tiveram uma maior circulação na então América portuguesa com a chegada do príncipe regente português e a consequente abertura dos portos, em janeiro de 1808, assim como a criação da Impressão Régia, em maio do mesmo ano e da promulgação da Carta Régia de 28 de janeiro de 1808, documento que concedia 0 direito aos habitantes da colônia de importarem bens de outras localidades que não Portugal, estando uma boa parte do comércio de livros existente nas mãos dos franceses (OLIVEIRA, 2016). O domínio cultural exercido pela França proporcionou aos editores, oportunidades comerciais em muitos mercados estrangeiros somados a uma receptividade excepcional a todos os adornos da cultura francesa (HALLEWELL, 2005).

Assim, a língua francesa, segundo Hazard (1971), já há muito assumia o status de língua universal e, ao cruzar o Atlântico, em um momento de início de formação do Brasil, seus valores culturais passaram a fazer parte também da vida brasileira. Este artigo é parte de um trabalho de mestrado em Educação ${ }^{1}$ que tratou da institucionalização do ensino de francês no Brasil quando da chegada da família real e de sua corte. Nesta oportunidade, gostaria de pensar o ensino de francês por meio dos livros, os compêndios de francês, ou, como bem defende

\footnotetext{
${ }_{1}$ Defendido no ano de 2016 na Universidade Tiradentes, no Estado de Sergipe, Nordeste brasileiro, o trabalho de investigação A INSTITUCIONALIZAÇÃO DO ENSINO DE FRANCÊS NO BRASIL: o caso da Academia Real Militar do Rio de Janeiro (1810 - 1832) foi realizado com apoio da Coordenação de Aperfeiçoamento de Pessoal de Nível Superior - Brasil (CAPES) - Código de Financiamento 001.
} 


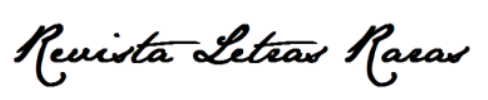

ISSN: 2317-2347 - v. 9, Dossier spécial (2020)

Todo o conteúdo da RLR está licenciado sob Creative Commons Atribuição 4.0 Internacional

Hallewell (2005), os "mediadores da expressão dos valores culturais de um povo", disponíveis como material didático no território brasileiro ainda na primeira década de 1800.

Situada entre os períodos colonial e imperial brasileiros, um tempo de grande instabilidade política e de escassas fontes para os estudos acadêmicos sobre a história do Brasil, o levantamento bibliográfico desta investigação foi realizado nos espaços virtuais das bibliotecas nacionais do Brasil, Portugal e França, ao que podemos classificá-la como uma pesquisa bibliográfica-documental. Quatro compêndios foram analisados quanto aos seus conteúdos de ensino que repercutem para nós as ideias pedagógicas e políticas que os fundamentavam. Estes livros, escritos em língua francesa foram adotados como material didático em instituições de ensino na então América portuguesa, a exemplo da Academia Real Militar do Rio de Janeiro, criada em 1810 (OLIVEIRA, 2016). A tradução e/ou versão da produção francesa era uma orientação conferida ao Lente da cadeira de Línguas Estrangeiras, sendo estas obras as primeiras publicações da Impressão Régia recentemente constituída no Brasil (HALLEWELL, 2005).

Como Compère e Chervel (1999) defendem, os livros didáticos são uma das principais fontes para a história das disciplinas escolares, trazendo para o pesquisador as necessárias condições de análise dos conteúdos pedagógicos propostos. No momento histórico em que nos situamos, o francês está em vias de se firmar como disciplina escolar, por isso a natureza das obras analisadas ser tão heterogênea, indo de apontamentos dos usos oral e escrito à gramáticas bilíngues. Compère e Chervel (1999) enfatizam a importância de se "refazer a historiografia educacional" em busca de "novas fontes" afim se obter novas perspectivas de estudo para a História da Educação. Dessa forma, defendemos a ideia de que estes livros são uma das principais fontes para a história das disciplinas escolares, mais especificamente, para a história do ensino de francês como língua estrangeira no Brasil oitocentista, uma narrativa ainda com poucas linhas escritas, apesar do longo período de hegemonia entre nós como disciplina escolar. Não proponho nesta oportunidade uma análise desses compêndios no tocante à metodologia empregada para o ensino do francês, mas sim um estudo da composição de seus conteúdos, uma vez que repercutem as ideias pedagógicas que os fundamentavam, assim como as finalidades políticas de seu ensino como saber institucionalizado.

O primeiro e mais antigo compêndio de francês elencado na pesquisa foi Remarqves Svr La Langve Françoise Vtiles A Cevx Qvi Vivevlent Bien Parler Et Bien Escrire, do senhor de 


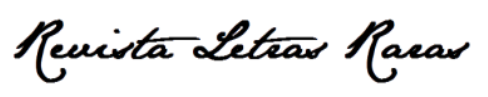

ISSN: 2317-2347 - v. 9, Dossier spécial (2020)

Todo o conteúdo da RLR está licenciado sob Creative Commons Atribuição 4.0 Internacional

Vaugelas, publicado na França em 1647. A segunda obra estudada é uma publicação holandesa lançada em 1696, de autoria de Pierre de La Touche e intitulada L'art De Bien Parler François. 0 estudo segue com a obra Grammatica Franceza, Ou Arte Para Aprender O Francez Por Meio Do Portuguez, Regulada Pelas Notas E Refflexoens Da Academia De França, de Luís Caetano de Lima, publicada pela primeira vez em Lisboa em 1710. Nesta pesquisa, descrevemos a edição portuguesa de 1756, pois o exemplar de lançamento encontra-se com acesso restrito na Biblioteca Nacional de Portugal. Dez anos depois, em 1766, foi publicado em Trevoux, França, sem precedentes, uma gramática bilíngue português-francês, de autoria desconhecida e publicada na oficina de António Ginião, intitulada por Novo, Facillimo Methodo De Grammatica Franceza, E Portugueza, Recopilado Dos Melhores Authores, Que Escreverão Artes, E Ortographisa, De La Rue, Restaut, E Galmace, La Touche, Desmarais, E Do Tratado Da Orthographia Franceza,... Ordenado Por Hum Genio Amante, Dos Progressos Dos Estudiosos Deste Idioma, o quarto e último compêndio elencado para análise.

20 ensino de francês pelo "bom uso": Remarqves Svr La Langve Françoise Vtiles A Cevx Qvi Vevlent Bien Parler Et Bien Escrire, de Vaugelas.

De autoria de Claude Favre de Vaugelas, o senhor de Vaugelas (1585-1650), 0 compêndio para o ensino de francês Remarqves Svr La Langve Françoise, publicado em Paris, em outubro de 1647, é sem dúvida uma obra de referência no mercado editorial ainda hoje, com exemplares publicados nos anos $2000^{2}$. O autor buscou com esta obra fazer remarques sobre a língua francesa, ou seja, registrar em forma de notas, ao longo de quinhentas e noventa e três páginas, observações sobre o francês escrito e falado, nos apresentando, a natureza de seu trabalho já em seu título.

\footnotetext{
2 A última edição de Remarqves Svr La Langve Françoise foi lançada em 2009, em Genève, pela editora Droz. Fonte: https://www.data.bnf.fr/.
} 


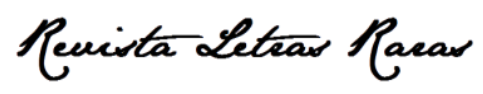

ISSN: 2317-2347 - v. 9, Dossier spécial (2020)

Todo o conteúdo da RLR está licenciado sob Creative Commons Atribuição 4.0 Internacional

Escrita em língua francesa, a obra não se preocupa com o estabelecimento de uma regulamentação da língua, não tendo a intenção de "[...] reformar nossa língua (francesa), nem de abolir nossas palavras, mas somente mostrar o bom panorama dos fatos, se ele é duvidoso ou desconhecido, o esclarecendo, o fazendo conhecido" 3 (VAUGELAS, Prefácio, 1647, tradução nossa $\left.{ }^{4}\right)$. Escrevendo um simples testemunho, Vaugelas documentou o que "viu e ouviu" na corte francesa, apresentando em seu texto o conceito de "uso" da língua, nos processos de fala e de escrita, pensando a linguagem em seu uso ${ }^{5}$, muito antes do surgimento da linguística (VAUGELAS, Prefácio, 1647).

Segundo as notas de seu prefácio, a obra Remarqves Svr La Langve Françoise foi elaborada a partir de anotações das conversações de festas frequentadas pelo seu autor na corte do Rei Sol. Durante o reinado de Luís XIV (1638-1715), a ascensão da literatura francesa transformou profundamente a formação da nobre juventude. A querela entre antigos e modernos $^{6}$, sem implicações diretas no plano educativo, trouxe uma concepção vanguardista para as letras ${ }^{7}$, pois, segundo os ilustrados, "[...] o centro de gravidade da cultura literária e artística adiantou-se alguns REMARQVES $S$ V R L A LANGVE FRANÇOISE VTILES A CEVX QVI VEVLENT BIEN PARLER ET BIEN ESCRIRE.
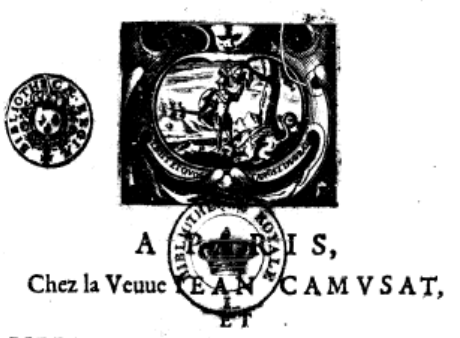

PIERRE LE PE TIT, Imprimeur \& Libraire ordinaire du Roy, ruë Sainct Iacques, à la Toifon d'Or. M. DC. XLVII. AVEC PRIVILEGE DV ROY.

Figura 1. Capa de compêndio de ensino de francês publicado em 1647. (VAUGELAS, 1647) Fonte: < http://catalogue.bnf.fr/ark:/12148/ cb31548981f > Acesso em: 02 março. 2015. milhares de anos" (CHERVEL; COMPÈRE, 1999, p. 156). A pedagogização de autores franceses para o uso da juventude escolar, na virada

\footnotetext{
3 Texto original: «[...] de reformer nostre langue, n'y d'abolir des mots, n'y d'en faire, mais seulement de monstrer le bon usage de ceux qui sont faits, et s'il est douteux ou inconnu, de l'esclaircir, \& de le faire connoistre» (VAUGELAS, Préface, 1647).

4 Todas as traduções apresentadas são de responsabilidade da autora do texto.

5 Sobre o conceito de língua e suas abordagens teóricas consultar o artigo 0 conceito de língua: um contraponto entre a Gramática Normativa e a Linguística (NASI, 2007).

${ }^{6}$ Intelectuais franceses pertencentes à Academia de Letras discutiram se deveriam exaltar Luis XIV, o rei-sol, recorrendo às citações dos clássicos do mundo greco-romano ou se deveriam inspirar-se em obras mais próximas, da história do cristianismo ou do presente. Esta discussão, iniciada em Paris no ano de 1687, abriu caminho para a crescente valorização do Moderno como oposto ao Antigo (OLIVEIRA, 2014).

7 "As letras, que designavam o conjunto do saber, incluindo também as ciências, têm de limitar seu sentido por volta de 1720, às obras literárias" (CHERVEL, COMPĖRE, 1999, p. 157).
} 


\section{Penista Leteas Parar}

ISSN: 2317-2347 - v. 9, Dossier spécial (2020)

Todo o conteúdo da RLR está licenciado sob Creative Commons Atribuição 4.0 Internacional

do século XVII para o XVIII, assim como a adoção, por grande parte dos países europeus e seus domínios da língua e cultura francesas, fez com que, pouco a pouco, o francês ocupasse um terreno até então dominado exclusivamente pela língua latina.

A língua escrita pelo senhor de Vaugelas era, portanto, o espelho do discurso que ele transcrevia, por assim dizer, em grafema. Assim, a codificação da língua falada, ou seja, a língua escrita, nomeada por "língua imagem", ou a língua escrita dos "Autores", pode ser encarada como um registro do uso da língua francesa pela corte. A representação social desta língua vinha da corte francesa, que assumiu um valor absoluto na descrição de seu bom uso.

A palavra que se pronuncia é a primeira em ordem e em dignidade, pois sendo ela escrita é somente a sua imagem [...]. Mas o consentimento dos bons Autores é como um selo ou uma atestação que autoriza a língua da Corte, e que marca o bom uso e decide aquilo que é duvidoso ${ }^{8}$ (VAUGELAS, Prefácio, 1647).

De acordo com as tendências de seu século, Vaugelas buscou princípios que permitiriam descrever e explicar o uso da língua francesa defendendo a subordinação da língua escrita à língua falada e buscando distinguir o seu "bom uso" do seu "mau uso" (VAUGELAS, Prefácio, 1647). Baseado na hierarquia social, sendo atribuído à corte o mais alto prestígio linguístico, o bom uso da língua francesa era definido como "composto não da pluralidade, mas pela elite das vozes" ${ }^{9}$, pela elite da comunidade linguística (VAUGELAS, Prefácio, 1647).

Eis então como é definido o bom uso. É a maneira de falar da mais sadia parte da Corte, conforme a maneira de escrever da mais sadia parte dos Autores do tempo [...]. Quando eu digo a Corte, eu entendo as mulheres como os homens e várias pessoas da cidade onde o Príncipe reside, que pela comunicação que ele tem com as pessoas da Corte utilizam de sua polidez (VAUGELAS, Prefácio, 1647) ${ }^{10}$

O que Vaugelas chama por "uso duvidoso" da língua francesa é definido como "aquilo que não se sabe" (VAUGELAS, Prefácio, 1647). Sendo, neste caso, "necessário consultar os

\footnotetext{
8 Texto original: « [...] la parole qui se prononce, est la premiere en ordre et en dignité, puis que celle qui est escrite n'est que son image [...]. Mais le consentement des bons Autheurs est comme le sceau, ou une verification, qui authorise le langage de la Cour, et qui marque le bon Vsage, et décide celuy qui est douteux» (VAUGELAS, Prefácio, 1647).

9Texto original: «composé non pas de la pluralité, mais de l'élite des voix»

10 Texto original: « Voicy donc comme on définit le bon Vsage. C'est la façon de parler de la plus saine partie de la Cour, conformément à la façon d'escrire de la plus saine partie des Autheurs du temps [...]. Quand ie dis la Cour, i'y comprens les femmes comme les hommes, et plusieurs personnes de la ville où le Prince réside, qui par la communication qu'elles ont auec les gens de la Cour participent à sa politesse» (VAUGELAS, Prefácio, 1647).
} 


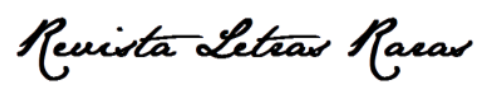

ISSN: 2317-2347 - v. 9, Dossier spécial (2020)

Todo o conteúdo da RLR está licenciado sob Creative Commons Atribuição 4.0 Internacional

bons Autores vivos e todos estes que tenham particular conhecimento da língua", ou seja, os escritores (VAUGELAS, Prefácio, 1647). Tudo o que "a mais sadia parte da corte", ou seja, a alta nobreza definia por bom uso da língua era assim, por definição, "bonito e elegante" e deveria ser acatado pelos demais falantes da língua francesa (VAUGELAS, Prefácio, 1647).

\section{A exaltação do francês em L'art De Bien Parler François, de Pierre De La Touche}

L'art De Bien Parler François, Qui Comprend Tout Ce Qui Regarde La Grammaire \& Les Façons De Parler Douteuses foi publicado em 1696 na cidade de Amsterdam, um dos mais importantes centros editoriais do continente europeu. De autoria de Pierre De La Touche ( 16-- 1730), gramático francês refugiado no que hoje é o território da Holanda em decorrência da revogação do Edito de Nantes, esta obra é uma exaltação da língua e cultura francesas.

Nas primeiras páginas de seu longo prefácio, o autor posiciona-se como um defensor do ensino de francês e um admirador de sua língua materna caracterizando-a como "doce e forte", "simples e majestosa" (LA TOUCHE, 1696). Para além da francofonia, o ensino

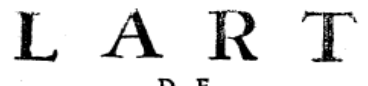

BIEN PARLER

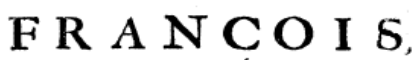

QUI COMPREND TOUT CE qui regarde la Grammaire \& les façons Divifé en deux Volumes.

TOME PREMIER.

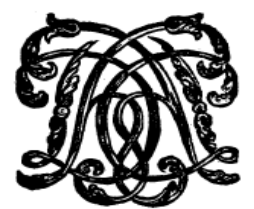

A A M T TERDAM

Chez HENRIDESBORDES, duns le Kalver-ftraat, près le Dam.

Figura 2. Capa de compêndio de ensino de francês publicado em 1696. (LA TOUCHE, 1696). Fonte: <http://catalogue.bnf.fr/ark:/12148/cb37228251g.>

de francês se apresentava como um

conhecimento necessário para a formação completa dos nobres, de reconhecida utilidade no ensino das ciências contemporâneas. La Touche (1696) afirmava que,

[...] Ela é geralmente preferida às demais línguas e os Estrangeiros de qualidade, até aos Príncipes Soberanos acreditam que lhes faltava algo em sua educação se eles não a falassem puramente e com facilidade [...] Ela é própria para todo tipo de matéria, para a prosa e para a poesia; para a 


\section{Reuista Leteas Racar}

ISSN: 2317-2347 - v. 9, Dossier spécial (2020)

Todo o conteúdo da RLR está licenciado sob Creative Commons Atribuição 4.0 Internacional

História e para o Romance, para os sérios e para o cômico (LA TOUCHE, Prefácio, 1696) ${ }^{11}$.

Escrita em francês e dividida em dois volumes, a obra foi sucesso editorial sendo ela reeditada até 0 ano de 197312. No primeiro volume, dividido em três partes, são abordados temas sobre a gramatização, conceito definido por Auroux (1992) como um fenômeno do século $\mathrm{XVI}$ que buscou fornecer elementos para a padronização dos vernáculos europeus, criando, com isso, uma rede de conhecimentos linguísticos. Na primeira parte do primeiro volume da obra de La Touche são explicadas questões referentes à pronúncia e à ortografia, consideradas por ele saberes difíceis e indispensáveis. A preocupação na elaboração de um pequeno resumo deste tópico em alemão, inglês, flamenco e italiano apresenta-se como uma novidade que garantiu uma circulação maior de sua obra.

Na segunda parte do compêndio são ponderadas questões sobre a natureza da palavra. Ganham destaque os Artigos, os Substantivos e sua variação em gênero, bem como a conjugação dos Verbos Regulares e Irregulares. A terceira e última parte do primeiro volume tocam em aspectos da Sintaxe, sendo dedicado um capítulo às qualidades do estilo e outro aos princípios da poesia francesa.

Para a construção de seu segundo volume, La Touche contou com a colaboração de alguns gramáticos franceses e procurou responder às dúvidas mais recorrentes sobre as normas gramaticais do ensino de francês. Buscando a praticidade na consulta de sua matéria, foi também elaborado, para este volume, um resumo com todos os pontos de aula, apresentados em ordem alfabética.

40 ensino de francês em português: Grammatica Franceza, Ou Arte Para Aprender 0 Francez Por Meio Do Portuguez, Regulada Pelas Notas E Refflexoens Da Academia De França, de Luiz Caetano de Lima.

\footnotetext{
${ }^{11}$ Texto original: «[...] Elle eft généralement préférée à toutes les autres, \& que les Etrangers de qualité, jufqu'aux Princes Souverains mêmes, croiroient qu'il manqueroit quelque chofe à leur éducation, s'ils ne la parloient purement $\&$ avec facilite [...]. Elle sft propre à toutes fortes de matières, pour la profe \& pour la poëfie; pour l'Histoire \& pour le Roman; pour le férieux \& pour le comique» (LA TOUCHE, Prefácio, 1696).

${ }^{12}$ A última edição de L'art De Bien Parler François foi lançada no ano de 1973, em Genève, pela editora Slatkine reprints. Fonte: https://www.data.bnf.fr/.
} 


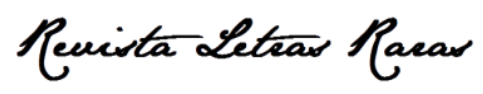

ISSN: 2317-2347 - v. 9, Dossier spécial (2020)

Todo o conteúdo da RLR está licenciado sob Creative Commons Atribuição 4.0 Internacional

Com todas as licenças necessárias para sua publicação é lançada a Grammatica Franceza, Ou Arte Para Aprender O

Francez Por Meio Do Portuguez, Regulada Pelas Notas E Refflexoens Da Academia De França, um dos mais antigos compêndios para 0 ensino de francês escrito em língua portuguesa. Publicada pela primeira vez em 1710 , em Portugal, com reedições que vão até 0 ano de 1911, esta obra apresenta-se em dois volumes. Foram, segundo seu autor, o clérigo português D. Luiz Caetano de Lima (1671-1757), membro da embaixada portuguesa enviada à Corte de Luís XIV em 169513, "quasi vinte annos de estudo" dedicados à elaboração desta
G R A M M A T I C A

FRANCEZA,

A $\mathbf{R}$ T E

PARA A PRENDER O FRA NCEZ por meyo da Lingua Pcrtugueza,

REGU UADA PELAS NOTAS, e Reflexoés da Academia de França..

P A R T E I. $P$ OR

D. LUiz CaEtano de lima, C. R.

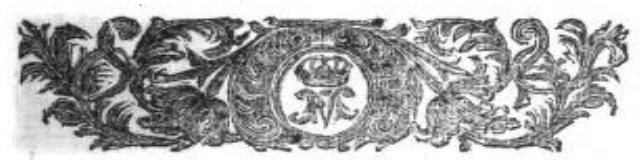

L I S B A, M.DCC.LVI.

Na Officin de JOSEPH DA COSTA COIMBRA. Con todas as licrasas nect/3atios.

Figura 3. Capa de compêndio de ensino de francês publicado em 1710. (LIMA, 1756). Fonte: <http://books.google.com/>. Acesso em: 13 abr. 2015.

"Grammatica Franceza e Portugueza" (LIMA, 1756). Para esta pesquisa, tomamos como fonte para análise apenas o primeiro tomo da obra, numa edição do ano de 1756, tendo em vista 0 restrito acesso às primeiras edições da Grammatica Franceza na Biblioteca Nacional de Portugal.

Escrito quando da passagem de seu autor nas cortes de Paris, Inglaterra e Holanda, esta obra pensou o ensino e a aprendizagem da língua francesa por "circumstancias géraes, transcendentes", que as diferenciavam do ensino e da aprendizagem das demais ciências, defendendo Lima uma especificidade para o ensino de francês (LIMA, 1756).

Confesso ingenuamente que esta obra me tem levado grande applicação, porque sempre entendi, que nas Linguas não há mediania alguma, como se observa nas outras Artes, e Sciencias; e assim, ou se devem fallar com toda

${ }^{13}$ Sobre a vida e obra de Luiz Caetano de Lima e sua missão como membro da embaixada portuguesa na França consultar Bem (1792-1794). 


\section{Penista Letraw Paras}

ISSN: 2317-2347 - v. 9, Dossier spécial (2020)

Todo o conteúdo da RLR está licenciado sob Creative Commons Atribuição 4.0 Internacional

a propriedade, ou não devem as pessoas grandes usar dellas (LIMA, Prólogo, 1756).

Como conteúdo programático apresentado em seu primeiro volume, os temas trabalhados são: "Dos Nomes, e números das letras; Da pronúncia das Vogaes; Da pronúncia das Consoantes; Dos Dithongos; Dos Trithongos; Dos Artigos, e Declinações; Dos Nomes; De algumas outras castas de Nomes; Dos Pronomes; Das Conjugações dos Verbos Irregulares" (LIMA, 1756).

Com a obra Grammatica Franceza foi lançado um "methodo de aprender huma lingua estrangeira", sem, contudo, esquecer-se da importância de sua língua nacional (LIMA, 1756). Segundo suas notas introdutórias, o ensino de francês é visto em sua utilidade como a língua da nobreza, a língua do comércio e da diplomacia, pois "Entre as linguas que mais facilitaõ o commercio das gentes, merece a lingua Franceza o principal lugar, e tem taõ grande fortuna com as testas Coroadas, que apenas se achará Principe algum, que despreze o seu uso" (LIMA, 1756, Prólogo).

O ensino de francês é também visto como o "primeiro elemento de todas as Sciencias", servindo este conhecimento não só como via de acesso aos textos das recentes descobertas nas Ciências Matemáticas, mas também como auxiliar no estudo da língua portuguesa (LIMA, 1756, Prólogo).

Os preceitos, que se escrevem nesta breve Grammatica taõ bem influem sobre a língua Portugueza, que filha da mesína Mãy, naõ he menos dotada, nem menos nobre, antes tem a vantagem de se associar na Asia ás linguas Orientaes por ser naquela primeira parte do Mundo, familiar a quasi todas as Naçoes (LIMA, 1756, Prólogo).

Assim, o discurso pragmático de Lima é inovador e sua gramática é, sem dúvida, original no estabelecimento de um método novo em Portugal e em seus domínios, o que incluía o Brasil. Lima construiu uma gramática bilingue que poderia haver noutras línguas, mas que até 1710 não existia para o português. Assim, trabalhando sem predecessores, o autor português muniu-se de referenciais franceses e fez uma sistematização, em português, dos aspetos que considerou mais pertinentes da língua francesa como "Dos accentos da Lingua Franceza" e os "Adverbios, e particularmente dos em Ement". 


\section{Reuista Leteas Racar}

ISSN: 2317-2347 - v. 9, Dossier spécial (2020)

Todo o conteúdo da RLR está licenciado sob Creative Commons Atribuição 4.0 Internacional

5 A "arte" de ensinar francês: Novo, E Facillimo Methodo De Grammatica Franceza, E Portugueza, Recopilado Dos Melhores Authores, Que Escreverão Artes, E Ortographisa, De La Rue, Restaut, E Galmace, La Touche, Desmarais, E Do Tratado Da Orthographia Franceza, ...Ordenado Por Hum Genio Amante, Dos Progressos Dos Estudiosos Deste Idioma, de António Ginião

Também escrito em língua portuguesa é o Novo, E Facillimo Methodo De Grammatica Franceza, E Portugueza, Recopilado Dos Melhores Authores, compêndio de francês publicado pela primeira vez na comuna de Trevoux, região de Rhône-Alpes, ao sul da França, no ano de 1766. A obra não tem sua autoria nomeada, sendo indicada apenas a Officina de António Ginião como o lugar da impressão desta que pode ser considerada uma espécie de compilação das produções da época sobre o ensino de francês para os falantes de língua portuguesa. 0 novo método de ensino proposto para "aprender com perfeição [...] a língua Franceza, e de algum modo a Portugueza" apresenta em mais de trezentas páginas "as artes" praticadas no ensino de francês em Portugal, entendendo "artes" como metodologias de ensino propostas pelos estudiosos da língua francesa no século XVIII (GINIÃO, Prefácio,

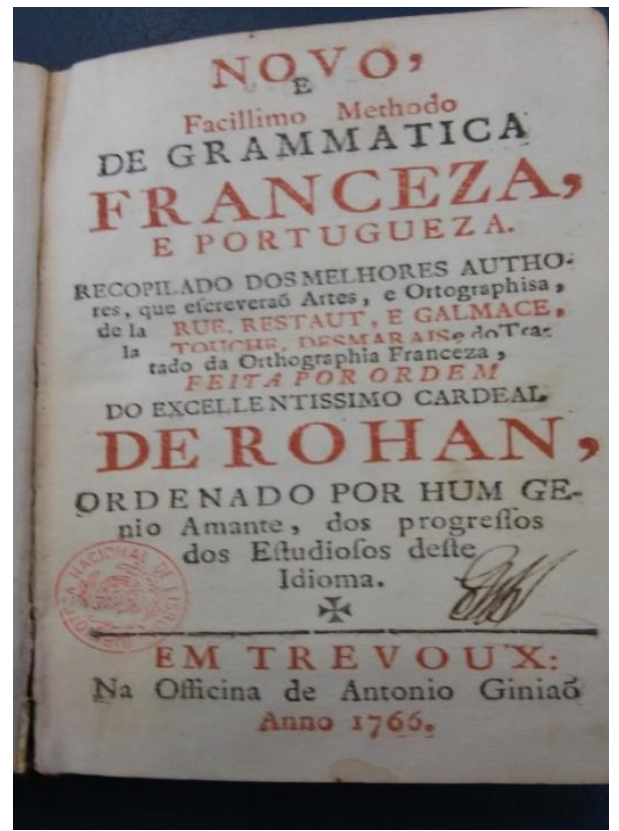

Figura 4. Capa de compêndio de ensino de francês publicado em 1766. Fonte: GINIÃO, António. Novo, E Facillimo Methodo De Grammatica Franceza, E Portuguesa, Trevoux: Off. De António Ginião, 1766. 1766).

Numa espécie de censura dos escritos submetidos ao Santo Ofício, o autor do Novo, $E$ Facillimo Methodo De Grammatica Franceza, E Portugueza condena as falhas cometidas por seus antecessores, citando dentre eles, o clérigo Luiz Caetano de Lima.

Muitas são as artes, que tem visto a luz pública a fim de ensinar a língoa Franceza aos nossos Portuguezes; porém todas com alguma infelicidade. A do grande Lima he Antiga, e extensa [...] porém todas estas faltas verás agora corregidas nesta Arte, da qual não digo mais, porque o teu mesmo sufrágio será o seu elogio (GINIÃO, Prefácio, 1766). 


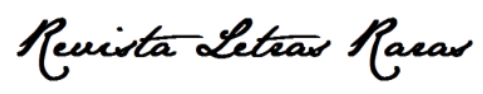

ISSN: 2317-2347 - v. 9, Dossier spécial (2020)

Todo o conteúdo da RLR está licenciado sob Creative Commons Atribuição 4.0 Internacional

Buscando reparar os erros do passado cometidos pelos estudiosos do ensino de francês, a gramática bilíngue português-francês da Officina de António Ginião apresenta seus conteúdos de ensino divididos em cinco capítulos, sendo eles: "Capítulo I. Regras da Ortografia, e Pronunciação Franceza. Dos accentos, e figuras da Orthografia Franceza; Da pontuação; Das Vogaes simples; Dos Dithongos; Das consoantes; Do modo de lêr. Capítulo II. Das partes do discurso. Do nome Substantivo, e Adjectivo; Do Gênero; Do Numero; Do Caso; Do Artigo; Dos Pronomes; Dos gráos da Comparaçaõ; Das declinaçoens dos nomes. Capítulo III. Das propriedades do Verbo. Capítulo IV. Diálogos familiares; Capítulo V. De alguns Provérbios Franceses" (GINIÃO, Prefácio, 1766).

Percebemos expresso, tanto no prólogo da obra como no corpo de seu texto, nos exemplos de aplicação das regras gramaticais, o caráter instrumental atribuído ao ensino de francês, ratificando, dessa forma, sua hegemonia como conhecimento indispensável na construção do cristão útil.

Fico esperando, que te aplliques a tua lição com aquelle cuidado, e deligencia, que se precisa para formar hum homem util ao Rey, e ao Estado por meyo da língoa Franceza, a qual he geralmente reconhecida em toda a Europa por thesouro, em que se achaõ depositadas as riquezas de toda erudição (GINIÃO, Prólogo, 1766).

Para a "luz pública" da instrução portuguesa a que se refere o Novo, E Facillimo Methodo De Grammatica Franceza, E Portugueza, a "língoa Franceza" assumiu o papel de veículo de acesso a este universo de saberes e de erudição da cultura francesa numa espécie de linguagem de admissão à modernidade, do comércio e da diplomacia (GINIÃO, Prefácio, 1766).

\section{Sobre os compêndios de francês e suas finalidades de ensino nos oitocentos}

Descritos os conteúdos de ensino apresentados pelos quatro compêndios de francês que circularam no Brasil oitocentista, observamos o caráter instrumental como finalidade pedagógica de uma proposta utilitarista do ensino de francês como medida de uma política linguística do Estado iluminista português. O francês, como língua da nobreza, do comércio e da diplomacia, assume este modo instrumental a medida em que se normatiza, configurando-se como saber necessário para o exercício de uma função no moderno Estado que nascia. 


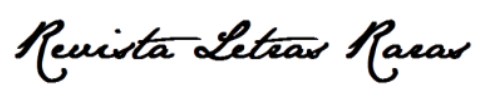

ISSN: 2317-2347 - v. 9, Dossier spécial (2020)

Todo o conteúdo da RLR está licenciado sob Creative Commons Atribuição 4.0 Internacional

No mais antigo compêndio a circular entre nós nos oitocentos, Remarqves Svr La Langve Françoise, não houve uma preocupação no trabalho de normatização da língua. Contudo, a justificativa para seu ensino baseou-se na hierarquia social, sendo atribuído à corte francesa o mais alto prestígio linguístico, configurando-se portanto como conhecimento necessário para a instrução de todo nobre.

Para além da francofonia, podemos afirmar que em L'art De Bien Parler François são levantadas questões sobre a gramatização quando nesta obra aparecem elementos de padronização do francês como regras de pronúncia e ortografia, por exemplo, saberes úteis na corte, nas trocas comerciais e na diplomacia.

Grammatica Franceza, Ou Arte Para Aprender O Francez Por Meio Do Portuguez, Regulada Pelas Notas E Refflexoens Da Academia De França foi o mais antigo compêndio para o ensino de francês escrito em língua portuguesa por nós pesquisado. Sua natureza bilíngue é inovadora para o ensino de português da época que se vê auxiliado pelo francês. Seu conhecimento assume portanto um caráter utilitário quando de seu espaço como veículo de acesso aos códigos de modernidade exportados pela França. Já em Novo, E Facillimo Methodo De Grammatica Franceza, E Portugueza, Recopilado Dos Melhores Authores, publicada na oficina de António Ginião como uma compilação das produções da época sobre o ensino de francês para os falantes de língua portuguesa, configura-se como recurso de censura das antigas metodologias de ensino de línguas. Essas metodologias de ensino

\section{Algumas considerações}

A história do ensino de francês nos oitocentos é uma história com poucas linhas, pois, para além das dificuldades de fontes de pesquisa deste século, o francês hoje não ocupa mais o lugar de prestígio como disciplina escolar, despertando raro interesse nos investigadores e nas instituições de fomento à pesquisa. Buscamos traçar algumas linhas desse enredo através de importantes livros utilizados no ensino de francês que entre nós circularam em 1800 . Percebemos na análise descritiva as diferentes maneiras de abordar o mesmo objeto, no caso, 0 ensino de francês como língua estrangeira, em um movimento que vai da contemplação da língua e de seu ensino como arte ao entendimento lógico e racional de transmissão desse saber pela gramática. 


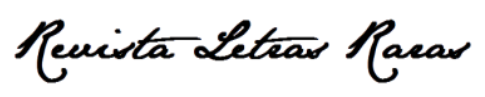

ISSN: 2317-2347 - v. 9, Dossier spécial (2020)

Todo o conteúdo da RLR está licenciado sob Creative Commons Atribuição 4.0 Internacional

Começamos com a mais antiga obra para o ensino de francês, um texto de 1647. Não podemos chamá-la de gramática porque a obra não se preocupa com o estabelecimento de uma regulamentação da língua declarando uma subordinação da escrita pela fala. Ao descrever e explicar o uso da língua francesa, Vaugelas deixa para a posteridade um registro senão das normas, mas do uso da língua francesa de uma pequena parcela da França do século XVII: sua corte, tão imitava por toda Europa. A esta altura, segundo Chervel e Compère (1999), começava a utilização escolar do francês nas cortes europeias, mesmo que ainda coexistindo com o latim, já em declínio. Como matéria de ensino, o francês é exaltado por La Touche (1696) que ao dar ênfase à pronúncia e à ortografia, apresenta nessa história os primeiros elementos do processo de gramatização dos vernáculos europeus. Assim, a importância do ensino de francês aparece como elemento de formação da nobreza não só francesa, mas de toda a Europa ocidental pois garantiria o acesso aos modernos conhecimentos científicos produzidos no início do século XVI pois estes eram publicados em sua maioria em francês.

No movimento de ascensão dos vernáculos europeus, a gramática de Lima (1710), considerada a primeira bilíngue francês-português, defende uma especificidade para o ensino de francês não só como via de acesso aos textos das recentes descobertas nas Ciências Matemáticas, mas também como saber auxiliar no estudo da língua portuguesa. Este caráter instrumental é ainda mais marcante na obra de Ginião (1766) que se propõe como inventaria de todas as artes para o ensino do francês a língua como veículo de admissão ao novo saber, 0 científico, que despontava construindo de um novo tempo, uma nova sociedade e um novo homem: o iluminista.

\section{Referências}

AUROUX, Sylvain. A revolução tecnológica da gramatização. Tradução: Eni Puccinelli Orlandi. Campinas: Editora da Unicamp, 1992.

BEM, Tomás Caetano do. Memorias historicas, chronologicas da Sagrada Religião dos Clérigos Regulares em Portugal e suas Conquistas na India Oriental. Lisboa: Regia Officina Typografica, 17921794.

CHERVEL, André. História das disciplinas escolares: reflexões sobre um campo de pesquisa. Tradução: Guacira Lopes Louro. Teoria \& Educação. Porto Alegre, n. 2, p. 177 - 229. 1990. 


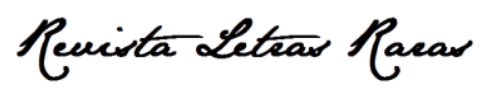

ISSN: 2317-2347 - v. 9, Dossier spécial (2020)

Todo o conteúdo da RLR está licenciado sob Creative Commons Atribuição 4.0 Internacional

CHERVEL, André; COMPĖRE, Marie-Madeleine. As humanidades no ensino. Tradução: Circe Maria Fernandes Bittencourt. Educação e Pesquisa. São Paulo, v. 25, n. 2, p. 149 - 170. 1999.

GINIÃO, António. Novo, E Facillimo Methodo De Grammatica Franceza, E Portuguesa, Recopilado Dos Melhores Authores, Que Escreverão Artes, E Ortographisa, De La Rue, Restaut, E Galmace, La Touche, Desmarais, E Do Tratado Da Orthographia Franceza, ... Ordenado Por Hum Gênio Amante, Dos Progressos Dos Estudiosos Deste Idioma. Trevoux: Off. De António Ginião, 1766.

HALLEWELL, Laurence. O livro no Brasil. Sua história. São Paulo: EDUSP, 2. Ed., 2005.

HAZARD, Paul. Crise da consciência europeia. Tradução: Oscar de Freitas Lopes. Lisboa: Cosmos, 1971. LAGES, Rita Cristina Lima. As vitrines da civilização: referências estrangeiras na instrução pública em Minas Gerais no século XIX. 2013. 265 f. Tese (Doutorado em Educação). Universidade Federal de Minas Gerais - MG. Disponível em: http://www.bibliotecadigital.ufmg.br/dspace/bitstream/handle/1843/BUBD9FYFES/tese.rita._cristi na.lima.lages.tese..2013.pdf?sequence=1 Acesso: 20 jun. 2014.

LA TOUCHE, Pierre de. L'art De Bien Parler François.Amsterdam: Chez Henri Desbordes, 1696. Disponivel em: http://catalogue.bnf.fr/ark:/12148/cb37228251g. Acesso em: 23 març. 2015.

LIMA, Luiz Caetano de. Grammatica Franceza, Ou Arte Para Aprender O Francez Por Meio Da Língua Portugueza, Regulada Pelas Notas E Refflexoes Da Academia De França.Lisboa: Joseph da Costa Coimbra, 1756. Disponível em: http://books.google.com/. Acesso em: 13 abr. 2015.

NASI, Lara. O conceito de língua: um contraponto entre a Gramática Normativa e a Linguística. Revista Urutágua - revista acadêmica multidisciplinar. Paraná, n. 13, ago./set./out./nov., 2007. Disponível em: http://www.urutagua.uem.br/013/13nasi.htm. Acesso em: 09 set. 2015.

OLIVEIRA, Kate Constantino P. A. A institucionalização do ensino de francês no Brasil: o caso da academia real militar do Rio de Janeiro (1810-1882). 2016. 106 p. Dissertação (Mestrado em Educação) - Universidade Tiradentes - SE. Disponível em: https://mestrados.unit.br/pped/wpcontent/uploads/sites/2/2016/03/DISSERTAC\%CC\%A7A\%CC\%82O-KATE-versa\%CC\%83o-pimpressa\%CC\%83o-2.pdfAcesso: 19 set. 2020.

OLIVEIRA, L. E. A instituição do ensino das Línguas Vivas no Brasil:o caso da Língua Inglesa (18091890). 2006. 378 f. Tese (Doutorado em Educação)-Pontifícia Universidade Católica de São Paulo - SP. Disponível em: http://www.sapientia.pucsp.br/tde_busca/arquivo.php?codArquivo=2255. Acesso: 05 jun. 2014. 


\section{Reuista Leteas Racar}

ISSN: 2317-2347 - v. 9, Dossier spécial (2020)

Todo o conteúdo da RLR está licenciado sob Creative Commons Atribuição 4.0 Internacional

VAUGELAS, Claude Favre de.Remarqves Svr La Langve Françoise Vtiles A Cevx Qvi Vevlent

Bien Parler Et Bien Escrire. Paris: Pierre Le Petit, Imprimeur\&Libraire ordinaire Du Roy, 1647.Disponivel em:http://catalogue.bnf.fr/ark:/12148/cb31548981f. Acesso em: 02 març. 2015. 